\title{
Risk aversion and technology portfolios *
}

\author{
Guy Meunier ${ }^{\dagger}$ \\ INRA-UR1303 ALISS \& Ecole Polytechnique
}

December 2013

\begin{abstract}
This paper analyzes the choice of a technology portfolio by risk-averse firms. Two technologies with random marginal costs are available to produce a homogeneous good. If the risks that are associated with the technologies are correlated, then the firms might invest in a technology with a negative expected return or, conversely, might not invest in a technology with a positive expected return. If the technology with the lower expected cost is riskier than the other technology, then this "low-cost" technology will be eliminated from the firm's portfolio if the risks are highly correlated. With imperfect competition, the portfolios of firms are different, and the difference in risk tolerance can explain the full specialization of the industry: The less risk-averse firms use the low-cost technology, and the more risk-averse firms use the less risky, higher-cost technology.
\end{abstract}

keywords: risk aversion, investment, technology mix

*The author gratefully acknowledges the support from the Business Sustainability Initiative at European Institute of Finance.

$\dagger_{\text {guy.meunier@ivry.inra.fr }}$ 


\section{Introduction}

In many industries, firms face random output and input prices. The electricity industry is a particularly striking example because uncertainties surround the prices of fossil fuels and $\mathrm{CO}_{2}$ emissions, the subsidy schemes that support renewable energies, the time to build new nuclear and coal plants, and the costs of efficient coal plants and carbon capture and storage facilities. These uncertainties influence the overall supply and the technology mix that is chosen by firms, especially if these firms are risk averse. Investment in a technology could be deterred because of risk and risk aversion, and this impediment could be linked to industry structure.

This paper analyzes the supply of an industry that is composed of risk-averse firms. In the model used here, two technologies are available, and each firm must decide how much to produce with each technology. One technology has a lower expected marginal cost than the other and would be the sole technology used absent risk aversion. However, a firm can diversify its portfolio by investing in the other more costly technology to reduce its risk. The influence of correlation is emphasized.

The supply of a single firm indicates that higher prices are associated with lower shares of the low-cost technology in a firm's technology "portfolio". If risks are sufficiently correlated, then the firm does not invest in the low-cost technology, but instead solely invests in the high-cost one if the output price is relatively high. Thus, risk and risk aversion can explain how a low-cost technology is driven out of a firm's portfolio.

Industry equilibrium with price-taking and Cournot competitors is described. With perfect competition, all firms have the same portfolio of technologies. The total industry supply is determined by the aggregate risk aversion of the industry and the demand function. The risk aversion of a particular firm only determines its size, not the composition of its portfolio. ${ }^{1}$ With Cournot competition, this feature does not hold because less risk-averse firms not only produce more but also have a larger share of the low-cost technology. At equilibrium, relatively large firms may specialize in the low-cost technology while smaller firms may specialize in the high-cost technology.

This specialization is endogenous and not assumed. Large firms are not large because they have privileged access to the low-cost technology but because they are less risk averse. Small firms are not prevented from using the low-cost technology because of some fixed cost (e.g., patent fees) but solely because of the risks and a firm's risk aversion. That is, risk aversion determines both a firm's size and its expected marginal production cost.

The rest of the paper is organized as follows: In the next section the relationship of this work to the literature is reviewed. Then, the model is introduced (Section 3). The model is first used to analyze the supply of a single firm (Section 4) and then the market equilibrium with either perfect competition or

\footnotetext{
${ }^{1}$ The similarity of all firms' portfolios is reminiscent of a feature of the Capital Asset Pricing Model: Any investor's portfolio is a combination of the market portfolio and a risk-free asset (see Sharpe, 1991, for a nice exposition).
} 
Cournot competition (Section 5). The robustness of the results are discussed in Section 6. Section 7 concludes.

\section{Literature review}

The relationship of this work to the general literature on firms and risk is first reviewed, and then the issue of technology choices in electricity markets is discussed.

Whether firms are or should be risk averse is an important theoretical and empirical question. Theoretically, with a complete set of markets the profit of a firm is determinate and its risk does not matter. Diamond (1967) analyzed the role of the stock market when output markets are incomplete. He showed that the market equilibrium is Pareto optimal if firms maximize their expected profit and consumers use the stock market to hedge their risks. However, in the presence of incomplete markets, firms may act as though they are risk averse (see Banal-Estanol and Ottaviani, 2006, for a review). Several empirical studies support this behavior. ${ }^{2}$

The influence of risk aversion on a firm's production decisions has been analyzed in numerous contexts. Several authors have analyzed the influence of the output price uncertainty on a competitive, risk averse firm's production (Dhrymes, 1964; Baron, 1970; Sandmo, 1971). ${ }^{3}$ The main conclusions are that the more risk averse the firm is, the less it produces, and a risk-averse firm produces less as uncertainty increases.

With random input prices, Stewart (1978) shows that a risk averse firm overinvests in riskless factors (see also Blair, 1974; Okuguchi, 1977). The issue of technological diversification has not been analytically addressed.

The issue of risk aversion and investment has received significant attention in the literature on electricity markets. In this literature, risk and risk aversion are considered one possible explanation for the potential lack of investment in total capacity or in a particular type of technology. In electricity markets, the existence of a technology mix is fundamentally related to demand variability and the difference in the cost structures of technologies. This is not considered here (see Meunier, 2013, for an analysis of this issue), and the model constructed in this study should be interpreted as describing competition for base-load production in an electricity market.

Neuhoff and De Vries (2004) provided a formal analysis of the influence

\footnotetext{
${ }^{2}$ For instance risk aversion can explain corporate hedging activity (Amihud and Lev, 1981; Nance et al., 1993; May, 1995), and Wolak and Kolstad (1991) have empirically investigated how risk aversion explains the choices of risky coal suppliers by Japanese firms. More recently, Cronqvist et al. (2012) find a positive and robust relationship between corporate and CEOs' personal leverage, which suggests that firms may inherit the risk attitude of their CEOs or that the riskiness of a company may attract a like-minded CEO.

${ }^{3}$ Appelbaum and Katz (1986) and Haruna (1996) studied long-run industry equilibrium. The monopoly situation has been analyzed by Baron (1971) and Leland (1972). Strategic interactions recently have received attention, notably by Tessitore (1994), Wambach (1999), Asplund (2002) and Banal-Estanol and Ottaviani (2006).
} 
of risk and producer risk aversion on a producer's investment choice with a single technology. With regard to the technology mix, Roques et al. (2008) compared portfolios containing combined cycle gas turbine (CCGT), coal and nuclear plants. ${ }^{4}$ Fan et al. (2010) and Ehrenmann and Smeers (2011) used numerical simulations of an electricity industry equilibrium to assess the influence of generators' risk aversion on the total capacity built and on the technology mix.

Compared to these studies, the present paper offers a formal analysis of the determinants of the portfolio of a risk-averse firm and an industry. Even without any technical non-convexities (increasing returns to scale, minimal size, startup cost, ramping rates), risk could theoretically disqualify a low-cost technology (e.g. nuclear or renewable energy).

\section{Model}

A good that is sold at a price $p$ can be produced with two technologies, labeled $t=1,2$ with marginal cost $c_{t}+\theta_{t}$, where $\theta_{t}$ are random variables with $\mathbb{E} \theta_{t}=0$. The expected marginal cost of technology 1 is lower than the expected marginal cost of technology $2, c_{1}<c_{2}$. Therefore, technology 1 is called the "low-cost" and technology 2 the "high-cost". Standard deviations are denoted by $\sigma_{t}$ for $t=1,2$, covariance by $\sigma_{12}$ and the correlation by $\rho=\sigma_{12} / \sigma_{1} \sigma_{2}$. It is assumed that the random variables are not perfectly correlated: $\rho \neq-1,1 .^{5}$ When $t$ is used to denote one of the technologies $s$ is used for the other: $s, t=1,2$ and $s \neq t$.

The good is produced by an industry that consists of a set $I$ of $n$ firms. The production of firm $i$ in $I$ is denoted by $q^{i}$, which is the sum of firm $i$ 's production with technology $1, q_{1}^{i}$, and technology $2, q_{2}^{i}$. The aggregate quantity that is produced by all firms is $Q$ :

$$
Q=\sum_{i \in I} q^{i}=\sum_{i \in I}\left[q_{1}^{i}+q_{2}^{i}\right]
$$

The demand side is represented by the price function $P(Q)$. This price function is continuous and decreasing, and it is positive and twice differentiable for $Q$ in $[0, \bar{Q}]$, with $\bar{Q}>0$ and null for $Q>\bar{Q}$. The function satisfies the following condition :

$$
\forall Q \in[0, \bar{Q}], P^{\prime \prime}+P^{\prime} Q>0
$$

This assumption, which is common in the industrial organization literature, implies that the marginal revenue of a firm is decreasing with respect to the production of its rival. Thus, quantities are strategic substitutes, and the existence and uniqueness of the Cournot equilibria are ensured. ${ }^{6}$

\footnotetext{
${ }^{4}$ The use of financial portfolio techniques (Markowitz, 1952) to evaluate the diversification of power producing utilities was first used in the 'regulated era' and was initiated by Bar-Lev and Katz (1976). Such an analysis has additionally been used by several authors to evaluate national portfolios (e.g. Humphreys and McClain, 1998; Awerbuch and Berger, 2003).

${ }^{5}$ The correlation of two random variables is between -1 and $1: \sigma_{12} \leqslant \sigma_{1} \sigma_{2}$.

${ }^{6}$ Equivalently, functions $x \rightarrow p^{\prime}(x+y) x$ are decreasing for all $\mathrm{y}$.
} 
For $i$ in $I$ the profit of firm $i$ is as follows:

$$
\pi^{i}=\pi\left(p, q_{1}^{i}, q_{2}^{i}, \theta_{1}, \theta_{2}\right)=p q^{i}-\left(c_{1}+\theta_{1}\right) q_{1}^{i}-\left(c_{2}+\theta_{2}\right) q_{2}^{i} .
$$

The firm is assumed to maximize a mean-variance utility function where $\lambda^{i}>0$ represents its risk aversion:

$$
U\left(p, q_{1}^{i}, q_{2}^{i}\right)=\mathbb{E} \pi^{i}-\frac{\lambda^{i}}{2} \operatorname{var}\left(\pi^{i}\right) .
$$

The risk is only represented by the variance of the firm's profit, and the firm's risk aversion measures how the firm weights the variance compared to the expected profit. The variance of a firm's profit will be simply referred to the firm's risk. With this specification a risk-averse firm is similar to a risk-neutral firm with convex costs. Risk-aversion explains how the supply of a firm is finite, even if the price of the good is higher than the marginal cost of the low-cost technology.

The quantities of goods that are produced by a firm are better interpreted as quantities of producing plants with the implicit assumption that once a firm has invested in plants, the firm produces at full capacity for all cost realizations. With this interpretation, marginal costs are long term marginal costs and include both fixed capacity costs and variable production costs. Issues that are related to plant flexibility and the ratio between capacity costs and variable costs are not considered. It is implicitly assumed that the firm can borrow capital at a risk-free rate.

Output price risk is not explicitly introduced, but, thanks to the additivity of the framework, output price risk is included in marginal cost risks $\theta_{1}$ and $\theta_{2}$ and can explain a positive correlation between the random variables $\theta_{1}$ and $\theta_{2}$.

\section{The supply curve}

In this section, the supply of a single price-taking firm is described. The subscript $i$ is dropped to simplify the exposition. The firm chooses the quantity of each technology to maximize its utility, given by equation (3). For technology $t$, denoting $\nu_{t}$ the Lagrange multiplier of the positivity constraint, the Kuhn-Tucker conditions are:

$$
\begin{array}{r}
p-c_{t}=\frac{\lambda}{2} \frac{\partial}{\partial q_{t}} \operatorname{var}(\pi)+\nu_{t} \\
\nu_{t} q_{t}=0 \text { and } \nu_{t} \geq 0, q_{t} \geq 0 .
\end{array}
$$

Equation (4) describes the trade off made by a risk-averse firm: The firm compares the expected return from each unit produced with the effect of this unit on the variance of the firm's profit.

A firm does not use a technology $\left(\nu_{t}>0\right.$ in 4$)$ if the production of the first unit with this technology has a larger weighted effect on the firm's risk than the 
technology 's expected return $\left(p-c_{t}\right)$. If the two technology risks, $\theta_{1}$ and $\theta_{2}$, are independently distributed, then the first unit produced with a technology has no effect on the firm's risk because the return from this unit is uncorrelated with the returns of the firm's other units. With independent risks, a firm invests in a technology if and only if the price of the good is above the technology's expected marginal cost. This equivalence does not hold with correlated risks.

First, if technology risks are negatively correlated, the cost of technology 2 is likely to be low when the cost of technology 1 is high. Therefore, producing one unit with technology 2 reduces the variation in the firm's profit if the firm produces mainly with technology 1 . In such a case, a firm may benefit from using technology 2 to hedge production with technology 1, even though the expected return from technology 2 is negative (cf Proposition 1 below).

Second, if costs are positively correlated, the first unit produced with a technology will increase the risk faced by the firm if the firm already uses the other technology. In such a case, the firm might not invest in a technology even if the price of the good is above the expected marginal cost of that technology (cf Propositions 2 and 3).

If the firm uses both technologies, the quantities produced satisfy the pair of first order conditions (4) with $\nu_{t}=0$. Since the variance of the profit is $\sigma_{1}^{2} q_{1}^{2}+\sigma_{2}^{2} q_{2}^{2}+2 \sigma_{12} q_{1} q_{2}$, the first order conditions are

$$
p-c_{t}=\lambda\left(\sigma_{t}^{2} q_{t}+\sigma_{12} q_{s}\right)=\lambda \sigma_{t}^{2}\left(q_{t}+\rho \frac{\sigma_{s}}{\sigma_{t}} q_{s}\right), t=1,2 .
$$

Two threshold prices are worth introducing:

$$
p_{1}=\frac{\sigma_{2} c_{1}-\rho \sigma_{1} c_{2}}{\sigma_{2}-\rho \sigma_{1}} \text { and } p_{2}=\frac{\sigma_{1} c_{2}-\rho \sigma_{2} c_{1}}{\sigma_{1}-\rho \sigma_{2}} .
$$

These prices are derived (cf appendix A) from the expressions of the solutions of equations (6). The firm's supply and the share of each technology depend on the value of the variances and the correlation of the marginal costs. Before going into those considerations in greater detail, a general characteristic of the technology portfolio can be established:

Lemma 1 The share of the low-cost technology in the firm's total production, $q_{1} / q$ decreases with respect to the output price.

When the output price increases, the firm increases its total production and progressively invests in an increasing share of the high-cost technology. The share of technology 1 in the firm's portfolio monotonically converges toward a limit that will depend on the risk parameters.

The technology mix is determined by a trade off between costs and risk reductions. As the total production increases, the cost motive that favors technology 1 becomes dominated by the risk-reduction motive because the risk is a second-order phenomenon that rises with the square of the total production. The share of the low-cost technology asymptotically approaches the value that 
minimizes the risk that is associated with the production of one unit. ${ }^{7}$ This risk-minimizing mix depends only on the risk parameters. The share of technology 1 in this asymptotic mix could be between 0 and 1 (Proposition 1) or null (Proposition 2) or unity (Proposition 3).

Proposition 1 If $\rho \leq \min \left\{\sigma_{1} / \sigma_{2}, \sigma_{2} / \sigma_{1}\right\}$, then:

- for $p<p_{2}$, the firm only invests in technology $1, q_{2}=0$;

- for $p \geq p_{2}$, the firm invests in both technologies and both quantities increases with respect to the output price.

Furthermore, the threshold price $p_{2}$ is lower than $c_{2}$ if and only if risks are negatively correlated.

The proof can be found in appendix A. At a low output price, the firm only invests in the low-cost technology. At a high price, the firm diversifies its technology portfolio by investing in the second technology. There are situations in which the firm invests in technology 2 even though its expected marginal cost is below the price. Such a situation occurs if and only if the technology risks are negatively correlated. With a positive correlation, the threshold price is higher than the expected cost, which means that there is a range of prices that are higher than the expected cost of technology 2 but do not trigger investment in that technology.

Proposition 2 If $\rho>\sigma_{2} / \sigma_{1}$ then $\sigma_{1}>\sigma_{2}$ and $p_{2}<p_{1}$ and:

- for $c_{1} \leq p \leq p_{2}$ the firm only invests in technology $1, q_{2}=0$;

- for $p_{2} \leq p \leq p_{1}$ the firm invests in both technologies;

- for $p_{1} \leq p$ the firm only invests in technology 2 .

The proof is in appendix A. For sufficiently high prices, not only does the firm invest in the high-cost technology, but it completely stops investing in the low-cost one. In such a case, a cheap technology is driven out of the firm's portfolio.

At a high enough price, cost considerations become negligible, and risk minimization favors technology 2. The risk-minimizing mix is fully comprised of technology 2 because the direct risk that is associated with technology 2 is low and the correlation between the two risks is large. Because of the positive correlation between the two technologies there is not much to gain from diversification, and the entire production should be performed with the technology with the lowest risk.

\footnotetext{
${ }^{7}$ Formally, if both of the technologies are used, subtracting the first-order condition that is associated with technology 2 from the one that is associated with technology 1 (cf. eqs. 6) and dividing by total production gives: $\left(c_{2}-c_{1}\right) /(\lambda q)=\left[\left(\sigma_{1}^{2}+\sigma_{2}^{2}-2 \sigma_{12}\right) q_{1} / q+\left(\sigma_{12}-\sigma_{2}^{2}\right)\right]$.
} 
Proposition 3 If $\sigma_{1}<\sigma_{2}$ and $\rho>\sigma_{1} / \sigma_{2}$ then the firm only invests in technology 1 for any price above $c_{1}$.

The proof can be found in appendix A. If the risk that is associated with the high-cost technology is large and both risks are highly correlated, the firm only invests in the low-cost technology regardless of the output price. The conjunction of the two features (high variance and high correlation) explains why diversification into the high-cost technology is not worthwhile because investing in this technology increases the firm's risk.

The technology mix of a firm does not depend on a firm's risk aversion if a firm is risk averse. The supply of a risk-neutral firm is dramatically different because for any price above $c_{1}$, a risk-neutral firm produces an infinite quantity and only uses technology 1. A risk-averse firm is limited in size because risk increases with the square of output, and a risk-averse firm uses technology 2 to limit risk. As the risk aversion of a firm decreases its total production tends toward infinity. However, the composition of the firm's portfolio does not change and can exhibit a discontinuity at zero. A risk-neutral firm completely disregards a huge risk, and thus systematically favors the low-cost technology.

If costs are convex, the risk aversion of a firm influences its technology mix. With quadratic costs and a similar slope of the marginal cost, the technology mix of a risk-averse firm still monotonically converges toward an asymptotic mix as the output price increases. The share of technology 1 still decreases with the output price because technology 1's first-order advantage would become negligible. The quadratic cost component does not become negligible as production increases. The asymptotic mix would be partly determined by the ratio between the marginal cost slope and the firm's risk aversion. In some situations, a firm may still use only one technology, but those cases involve a condition on the risk aversion of the firm. As risk aversion decreases, the technology mix tends toward the risk-neutral mix in which both technologies are used.

\section{Market equilibrium}

\section{Perfect competition}

If firms are price-takers, the equilibrium price clears the market so that supply equals demand. For any price $p$, the two quantities chosen by a firm are inversely proportional to its risk aversion (cf equation 6). Therefore, at equilibrium all quantities $\lambda^{i} q_{t}^{i}$ are equal across $i \in I$. This property allows for the consideration of a representative firm:

Lemma 2 With price-taking firms, the total supply of the $n$ firms is similar to the supply of a single producer with risk aversion $\Lambda$ defined by

$$
\Lambda=\left[\sum_{i \in I}\left(1 / \lambda^{i}\right)\right]^{-1} .
$$


For all $i \in I$, the production of firm $i$ with technology $t$ is a share $\Lambda / \lambda_{i}$ of the total production with technology $t$.

The parameter $\Lambda$ can be interpreted as a measure of the aggregate risk aversion of the industry. Expression (8) can be interpreted with the help of a parallel between risk aversion and productive capacity. Each firm has a productive capacity that is inversely proportional to its risk aversion, and total industry productive capacity is the sum of individual capacities.

Each firm's portfolio is proportional to the sector portfolio. The sectoral technology portfolio is optimal for each firm: 'optimal' in that the portfolio maximizes a firm's utility that is given by equation (3).

Corollary 1 An increase in the number of firms or a decrease in a firm's risk aversion decreases the output price and increases the share of the low-cost technology in each firm's portfolio and in the total portfolio.

The industry long-run equilibrium, with free entry, is not analyzed here. The industry is described by the set $I$, and the entry of a new firm is an exogenous addition of a new firm to $I$. Such an entry of a new firm in the industry is equivalent to a reduction of the sectoral risk-aversion parameter $\Lambda$ as though the supply side became less risk averse.

Though the result of this corollary is intuitive, the mechanism behind it is not. An increase in the number firms (a decrease in industry risk aversion) does not directly correct the mix toward the low-cost technology but indirectly via a reduction in the output price. When the number of firms grows, the portfolio converges toward the risk-neutral technology portfolio $\left(q_{1}=q\right)$ because the output price converges toward the marginal cost of the low-cost technology.

\section{Imperfect Competition}

In this section, we consider firms that compete $\grave{a}$ la Cournot. Each firm $i \in$ $I$ maximizes $U\left(p(Q), q_{1}^{i}, q_{2}^{i}\right)$. At equilibrium each firm's supply satisfies the following two first order conditions:

$$
p+p^{\prime} q^{i}=c_{t}+\frac{\lambda^{i}}{2} \frac{\partial}{\partial q_{t}^{i}} \operatorname{var}\left(\pi_{i}\right), \text { for } t=1,2, i \in I
$$

Compared to the perfectly competitive outcome, each firm faces a different marginal revenue at equilibrium, implying that the composition of firms' portfolios varies across the industry.

Proposition 4 For $i, j \in I$,

$$
\lambda^{i} \leqslant \lambda^{j} \text { if and only if } q^{i} \geqslant q^{j} \text { and } \frac{q_{1}^{i}}{q^{i}} \geqslant \frac{q_{1}^{j}}{q^{j}} .
$$

The proof is in Appendix B. In contrast to perfect competition, under imperfect competition, the firms' production choices differ by more than just firm size. The less risk averse firms produce more, and, facing a lower marginal revenue, their portfolios have a larger share of the low-cost technology. 
Corollary 2 For $i \in I$, a decrease in $\lambda^{i}$ has the following consequences:

(i) an increase in the production of firm $i$;

(ii) a reduction in production of all other firms;

(iii) an increase in the share of the low-cost technology in each firm's portfolio;

(iv) an increase or decrease in the share of the low-cost technology in the overall portfolio.

The portfolio of a firm is a function of the production of its competitors. The larger is this production, the smaller is the production of the firm and the larger the share of the low-cost technology in the firm's portfolio.

The reduction in the risk aversion of a firm induces all firms to increase the share of the low-cost technology in their portfolios via a reduction of the residual demand curve, but the reduction has an ambiguous effect on the overall portfolio. The evolution of the share of the low-cost technology in the industry portfolio could be decomposed into two components: the evolution of the individual shares of the low-cost technology, and the reallocation of production among firms. If total production is reallocated to the firms with a small share of the low-cost technology, it still possible, as illustrated below, that the total share of the low-cost technology decreases, even though individual shares increase.

Figure 1 illustrates this point in a duopoly with a linear price function $p=$ $1-Q .{ }^{8}$ There are two firms that are denoted $A$ and $B$. F irm $A$ is less risk averse than is firm $B$. The influence of a reduction of the risk aversion of firm $\mathrm{B}$ is depicted $\left(1 / \lambda_{B}\right.$ increases $)$.

As firm $B$ becomes less risk averse the total industry production increases, even though the production of firm $A$ decreases (cf. Figure 1(a)). The share of technology 1 increases in both firms portfolios; however, its share in the overall portfolio first decreases before increasing. The initial reduction of the share of technology 1 in the overall portfolio is due to the decrease in the total production of firm $A$. Although, the portfolio of firm $A$ becomes increasingly composed of technology 1 , the reduction of its total production compensates for this shift.

\footnotetext{
${ }^{8}$ The calculations for the linear specification are available upon request to the author.
} 


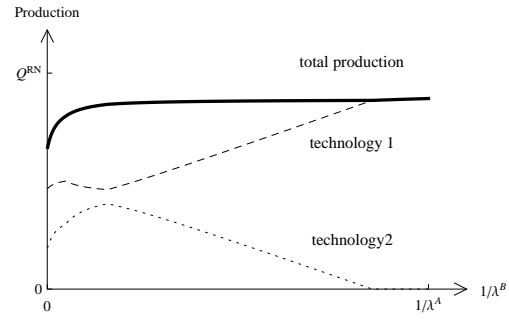

(a) The total production

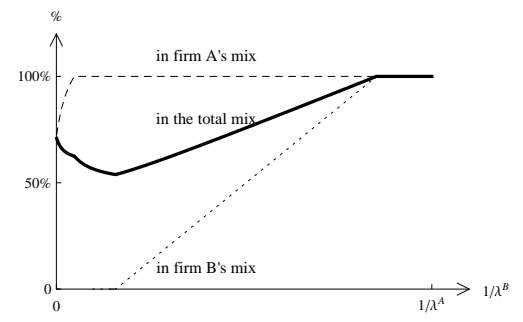

(b) The share of technology 1 in the total mix and in each firm's mix.

Figure 1: Evolution of the technology mix in a duopoly $\{A, B\}$ as the risk aversion of firm B decreases

Figure 1 additionally illustrates the possibility in a full specialization of the industry, with each firm using a different technology. The highly risk averse firm B only uses technology 2, while firm $A$ uses both technologies. As firm B becomes less risk averse, Firm $A$ specializes in technology 1 while firm $B$ continues to use only technology 2 . Accordingly, the industry is fully specialized, and firms use different technologies. As firm $B$ becomes even less risk averse, it starts using technology 1 , and, eventually, firm B also specializes in technology 1.

It is difficult to find the analytical conditions, even with a linear price function, that are necessary and sufficient for firms to use different technologies. However, the conditions of Proposition 2 must be satisfied for full specialization, and a sufficient condition for specialization could be described in the general case.

Corollary 3 If $\rho>\sigma_{2} / \sigma_{1}$, if the price with a risk neutral monopoly is larger than $p_{1}$, then, there are $\lambda^{A}$ and $\lambda^{B}$, with $\lambda^{A}<\lambda^{B}$, such that in a duopoly $I=\{A, B\}$, both firms produce a strictly positive quantity, and firm $A$ (resp. B) only uses technology 1 (resp. 2).

If the price with a risk-neutral monopoly is larger than the threshold price $p_{1}$, then for small $\lambda^{A}$, a monopoly with a risk aversion $\lambda^{A}$ results in a price that is also larger than $p_{1}$. For a large $\lambda^{B}$, firm $B$ will be sufficiently small such that its marginal revenue is above $p_{2}$, and the firm is specialized. It is feasible to calibrate a price function that satisfies this condition.

\section{General utility function}

In this section, we discuss how a more general representation of a firm's assessment of risks would affect the results. In a general model, a firm's objective is to maximize an expected utility function $\mathbb{E}[U(\pi)]$, with $U($.$) as a positive,$ increasing and strictly concave function. ${ }^{9}$

\footnotetext{
${ }^{9}$ The mean-variance utility function is a special case that corresponds to either a quadratic utility function, or a constant absolute risk aversion utility function and normally distributed
} 
The precise description of a firm's supply curve requires additional assumptions on the utility function or the distributions of risk; for instance, Lemma 1 could not be easily generalized. Furthermore, if each firm has a specific utility function, it is not possible to aggregate firms and obtain an industry's utility function. Consequently, price-taking firms may have different technological portfolios, or, more surprisingly, use different technologies.

The most robust results concern the effect of correlation on the selection of a technology. Correlation can explain why: i) a technology with a positive expected return is not used; and ii) a technology with a negative expected return is used.

For instance, the low-cost technology would not be used by a price-taking firm if (cf. appendix C)

$$
\operatorname{cov}\left(U^{\prime}(\pi), \theta_{1}\right) \geq \operatorname{cov}\left(U^{\prime}(\pi), \theta_{2}\right) \frac{p-c_{1}}{p-c_{2}},
$$

in which $\pi=\left(p-\theta_{2}-c_{2}\right) q_{2}$. This inequality could be satisfied only if $\theta_{1}$ and $\theta_{2}$ are positively correlated.

Many results would hold with a general utility function if risks are linearly related. For instance, for $\theta_{1}=\epsilon_{1}+r \theta_{2}$ with $\epsilon_{1}$ and $\theta_{2}$ independently distributed, the above inequality can be reduced to

$$
r \geq \frac{p-c_{1}}{p-c_{2}}>1
$$

Therefore, if the two risks are sufficiently correlated and the price is sufficiently large, a price-taking firm does not invest in the low-cost technology. ${ }^{10}$ This condition applies to all firms in a perfectly competitive industry, so that pricetaking firms all use the same technologies.

Another possibility is to parameterize the utility functions of the firms to ensure the existence of a representative firm. If firms are characterized by a multiplicative parameter, $U^{i}\left(\pi^{i}\right)=U\left(\lambda^{i} \pi^{i}\right)$ then the supply of a price-taking firm is homogeneous of degree -1 with respect to its risk aversion. ${ }^{11}$ The industry can be represented by a single firm with parameter $\Lambda$ that is given by the equation (8). The size of a firm, but not its portfolio composition is determined by $\lambda_{i}$. With imperfect competition, both the size and the composition of the portfolio are determined by $\lambda_{i}$.

Finally, instead of using utility functions, it is possible to consider a measure of risk that is more general than the standard deviation, and to represent a firm's risk aversion as the relative weight of risk. ${ }^{12}$ With a translation-invariant risk measure $\rho($.$) , a firm would maximize an objective$

$$
\mathbb{E}[\pi]-\lambda_{i} \rho(\pi)^{2}=\mathbb{E}[\pi]-\lambda_{i} \rho\left(\theta_{1} q_{1}^{i}+\theta_{2} q_{2}^{i}\right)^{2}
$$

risks, or a more general utility function but sufficiently small risks to allow for a second order approximation of the expected utility.

${ }^{10}$ Condition 10 corresponds to Proposition 3: The price $p_{1}$ defined by equation (7) is equal to $\left(r c_{2}-c_{1}\right) /(r-1)$ if $\theta_{1}=\epsilon_{1}+r \theta_{2}$.

${ }^{11}$ This finding is a direct result of $\lambda^{i} \pi\left(p, q_{1}^{i}, q_{2}^{i}, \theta_{1}, \theta_{2}\right)=\pi\left(p, \lambda^{i} q_{1}^{i}, \lambda^{i} q_{2}^{i}, \theta_{1}, \theta_{2}\right)$.

${ }^{12}$ The author would like to thank an anonymous referee for suggesting this possibility. 
If $\rho($.$) is homogeneous of degree one, firms' risk aversion can be aggregated and$ Lemma 2 is true (cf Appendix C). ${ }^{13}$ With a general measure of risk, higher moments than the variance of the distribution of the risks are relevant to the firms' decisions. To generalize the results of Section 4, the distribution of risks should be further specified, most notably the relationship between all the relevant moments of the distributions of $\theta_{1}$ and $\theta_{2}$. Indeed, the generality of the distribution of risks can be sacrificed for the generality of the risk-measure.

\section{Conclusion}

In this article, the technology portfolio of an industry of risk-averse producers has been analyzed in depth. The influence of the correlation between technology risks has been particularly emphasized. This correlation has a crucial influence on the equilibrium portfolio of firms. In particular, this correlation can deter firms from investing in a technology with a lower expected marginal cost and explain the full specialization of an industry in a technology with a larger expected marginal cost.

Furthermore, the analysis of the market equilibrium under perfect competition reveals that all price-taking firms have the same portfolio, but the firms differ with respect to their size. In addition, a larger number of firms is associated with a larger share of the low-cost technology in each firm's technology portfolio and in the industry portfolio. These results are altered with imperfect competition. In particular, with imperfect competition, firms with different degrees of risk aversion have different portfolios and, theoretically, risk aversion can cause each firm to specialize in one technology. Additionally, even though a reduction in the risk aversion of one firm increases the share of the low-cost technology in each firm's portfolio, this reduction can reduce the share of this technology in the overall portfolio.

\section{A Supply curve}

\section{Preliminary results}

The two first-order conditions (4) can be written:

$$
\lambda\left[\begin{array}{cc}
\sigma_{1}^{2} & \sigma_{12} \\
\sigma_{12} & \sigma_{2}^{2}
\end{array}\right]\left[\begin{array}{l}
q_{1} \\
q_{2}
\end{array}\right]=\left[\begin{array}{l}
p-c_{1} \\
p-c_{2}
\end{array}\right]
$$

Let us denote $x_{1}$ and $x_{2}$ the solutions of these equations (11)

$$
\left[\begin{array}{l}
x_{1} \\
x_{2}
\end{array}\right]=\frac{1}{\lambda \Delta}\left[\begin{array}{c}
\left(\sigma_{2}^{2}-\sigma_{12}\right)\left(p-c_{1}\right)+\sigma_{12}\left(c_{2}-c_{1}\right) \\
\left(\sigma_{1}^{2}-\sigma_{12}\right)\left(p-c_{1}\right)-\sigma_{1}^{2}\left(c_{2}-c_{1}\right)
\end{array}\right] .
$$

\footnotetext{
${ }^{13}$ The two properties-invariance by translation and homogeneity-are satisfied by a coherent risk measure (Artzner et al., 1999). See also the work of Zakamouline and Koekebakker (2009) on the relationship between risk-measures and the expected utility theory.
} 
where,

$$
\Delta=\sigma_{1}^{2} \sigma_{2}^{2}-\sigma_{12}^{2}=\sigma_{1}^{2} \sigma_{2}^{2}\left(1-\rho^{2}\right) .
$$

The threshold prices $p_{1}$ and $p_{2}$ in (7) are the solutions of the equations $x_{1}=0$ and $x_{2}=0$ (defined by eq. (12)) respectively Two useful expressions of these prices are:

$$
p_{1}=c_{1}-\frac{\rho \sigma_{1}}{\sigma_{2}-\rho \sigma_{1}}\left(c_{2}-c_{1}\right) \text { and } p_{2}=c_{1}+\frac{\sigma_{1}}{\sigma_{1}-\rho \sigma_{2}}\left(c_{2}-c_{1}\right) .
$$

Lemma A.1 The quantities $q_{1}(p, \lambda)$ and $q_{2}(p, \lambda)$ that maximize the firm's objective (3) are:

- if $x_{2} \leq 0$ then $q_{2}=0$ and $q_{1}=\left(p-c_{1}\right) /\left(\lambda \sigma_{1}^{2}\right)$;

- if $x_{2}>0$ and $x_{1} \leq 0$ then $q_{1}=0$ and $q_{2}=\left(p-c_{2}\right) /\left(\lambda \sigma_{2}^{2}\right)$;

- if $x_{1}>0$ and $x_{2}>0$ then $q_{1}=x_{1}$ and $q_{2}=x_{2}$.

wher $x_{1}$ and $x_{2}$ are defined by equation (12).

Proof.

There is unique solution to the firm maximization problem because its objective function is strictly concave (because $\lambda>0$ ).

If $\left(q_{1}, q_{2}\right)$ maximizes the firm's profit subject to the constraints $q_{t} \geq 0$ for $t=1,2$; then the Kuhn-Tucker conditions are:

$$
\begin{array}{r}
p-c_{1}-\lambda\left(\sigma_{1}^{2} q_{1}+\sigma_{12} q_{2}\right)+\nu_{1}=0 \\
p-c_{2}-\lambda\left(\sigma_{1}^{2} q_{2}+\sigma_{12} q_{1}\right)+\nu_{2}=0 \\
\nu_{t} q_{t}=0 \text { and } \nu_{t} \geq 0, q_{t} \geq 0
\end{array}
$$

in which, $\nu_{t}$ is the Lagrange multiplier that is associated with the inequality constraint $q_{t} \geq 0$. There is a unique couple $\left(q_{1}, q_{2}\right)$ solution of these equations.

a. $q_{1}=0, q_{2}=0$ if and only if $p<c_{1}$;

b. $q_{1}>0, q_{2}>0 \Leftrightarrow q_{1}=x_{1}, q_{2}=x_{2} \Leftrightarrow x_{1}>0, x_{2}>0$;

c. $q_{1}>0$ and $q_{2}=0 \Leftrightarrow q_{1}=\left(p-c_{1}\right) / \lambda \sigma_{1}^{2},\left(p-c_{2}\right)-\lambda \sigma_{12} q_{1} \leq 0 \Leftrightarrow p>$ $c_{1}$ and $x_{2} \leq 0$

d. $q_{1}=0$ and $q_{2}>0 \Leftrightarrow q_{2}=\left(p-c_{2}\right) / \lambda \sigma_{2}^{2}, x_{1} \leq 0 \Leftrightarrow p>c_{2}$ and $x_{1} \leq 0$.

Therefore, for $p>c_{1}$, the signs of $x_{1}$ and $x_{2}$ indicates what is the solution. If $x_{2} \leq 0$, then $q_{2}=0$ and $q_{1}=\left(p-c_{1}\right) / \lambda \sigma_{1}^{2}$ (by c). Otherwise, $x_{2}>0$, and $x_{1}$ is either positive or negative; if it is positive, then $x_{1}$ and $x_{2}$ are the solutions of the Kuhn-Tucker solutions (point b) and if $x_{1}$ is negative, then the only possibility left is $q_{1}=0$ and $q_{2}=\left(p-c_{2}\right) / \lambda \sigma_{2}^{2}$ (point d).

Note that, for $p>c_{1}$ the situation $x_{1} \leq 0$ and $x_{2}>0$ is possible only if $\sigma_{12}>0$ and $\left(p-c_{2}\right)>0$. Furthermore, it is possible that $p>c_{1}$ and both $x_{1}$ and $x_{2}$ are negative; in that case $q_{2}=0$ and $q_{1}>0$. 


\section{Proof of lemma 1}

Let us show that $q_{1}(p, \lambda) /\left(q_{1}(p, \lambda)+q_{2}(p, \lambda)\right)$ is increasing with respect to $p$. This function if continuous and differentiable by parts because $q_{1}$ and $q_{2}$ are differentiable. For $p>c_{1}$ three situations can arise: Either both quantities are strictly positive, or only one of them is positive. In the latter case the share of technology 1 is constant w.r.t. $p$ (it is either 1 or 0 ). In the former case the two first-order conditions (4) are satisfied, and both quantities are equal to $x_{1}$ and $x_{2}$. Taking the derivative of the equations 12 gives

$$
\left[\begin{array}{l}
\partial q_{1} / \partial p \\
\partial q_{2} / \partial p
\end{array}\right]=\frac{1}{\lambda \Delta}\left[\begin{array}{c}
\sigma_{2}^{2}-\sigma_{12} \\
\sigma_{1}^{2}-\sigma_{12}
\end{array}\right]
$$

And the sign of the derivative of the share of technology 1 in the firm's portfolio is the sign of (the numerator of its derivative):

$$
\frac{\partial q_{1}}{\partial p} q_{2}-\frac{\partial q_{2}}{\partial p} q_{1}
$$

which is equal to (from (12) and (18) and the expression of $\Delta 13$ ):

$$
\frac{1}{(\lambda \Delta)^{2}}\left[\left(\sigma_{2}^{2}-\sigma_{12}\right)\left(-\sigma_{1}^{2}\right)-\left(\sigma_{1}^{2}-\sigma_{12}\right) \sigma_{12}\right]=\frac{-1}{\lambda^{2} \Delta}<0 .
$$

\section{Proof of Proposition 1}

If $\rho<\min \left\{\sigma_{1} / \sigma_{2}, \sigma_{2}, \sigma_{1}\right\}$ then:

- $p_{1}<p_{2}$ :

- if $\rho \geq 0$ then from (14) $p_{1}<c_{1}<p_{2}$;

- if $\rho<0$ then, $(-\rho)\left(\sigma_{1}-\rho \sigma_{2}\right)<\sigma_{2}-\rho \sigma_{1}$ because $\rho^{2}<1$, and from (14), using $\rho<0, p_{1}<p_{2}$.

- $x_{t}$, for $t=1,2$, is increasing with respect to $p$ because $\sigma_{t}^{2}>\sigma_{12}$;

Then, for $p \in\left(c_{1}, p_{2}\right], x_{2} \leq 0$ so $q_{2}=0$ and $q_{1}>0$ by Lemma A.1; for $p \geq p_{2}$ then $p \geq p_{1}$ so $x_{1}>0$ and $q_{t}=x_{t}$ for $t=1,2$ and both quantities increase as the price increases. Furthermore, from (7) $p_{2}=c_{2}+\rho\left(c_{2}-c_{1}\right) \sigma_{2} /\left(\sigma_{1}-\rho \sigma_{2}\right)$ so $p_{2}<c_{2}$ if and only if $\rho<0$.

\section{Proof of Proposition 2}

If $\rho>\sigma_{2} / \sigma_{1}$ then $\sigma_{2}<\sigma_{1}$ because $\rho<1$. And, from 7

- $\left.p_{2}<p 1: \rho\left(\sigma_{1}-\rho \sigma_{2}\right)>\rho \sigma_{1}-\sigma_{2}\right)$ because $0<\rho<1$; then, $p_{2}<p_{1}$ from the expressions (14) of $p_{1}$ and $p_{2}$ and because $\sigma_{1}-\rho \sigma_{2}>0$ and $\rho \sigma_{1}-\sigma_{2}>0$.

- the proposition follows from the application of Lemma A.1. 


\section{Proof of Proposition 3}

If $\rho>\sigma_{1} / \sigma_{2}$ then $\sigma_{1}<\sigma_{2}$ and $x_{2}<0$ for any $p$ larger than $c_{1}$ from (12) and by Lemma A.1 the firm only invests in technology 1 .

\section{B Market Equilibrium}

Let us introduce a new notation to ease the exposition, $\Phi(p)$ is the total production of a firm with risk aversion 1 facing a price $p$ :

$$
\Phi(p)=q_{1}(p, 1)+q_{2}(p, 1) .
$$

This function is increasing with respect to $p: \Phi^{\prime}=\frac{1}{\Delta}\left[\sigma_{1}^{2}+\sigma_{2}^{2}-2 \sigma_{12}\right]>0$.

\section{Proof of Lemma 2}

the quantity produced with each technology by a price-taking firm facing price $p$, with risk aversion $\lambda$ are $q_{1}(p, \lambda)$ and $q_{2}(p, \lambda)$. From Lemma A.1 these functions satisfies:

$$
q_{t}(p, \lambda)=\frac{1}{\lambda} q_{t}(p, 1) \text { for } t=1,2
$$

At the industry level, for any price $p$ the supply of the industry with technology $t=1,2$ is:

$$
Q_{t}=\sum_{i \in I} q_{t}\left(p, \lambda^{i}\right)=q_{t}(p, 1) \sum_{i \in I} \frac{1}{\lambda^{i}}=\frac{1}{\Lambda} q_{t}(p, 1)=q_{t}(p, \Lambda)
$$

At the market equilibrium, the price $p^{*}$ satisfies:

$$
p^{*}=P\left(q_{1}\left(p^{*}, \Lambda\right)+q_{2}\left(p^{*}, \Lambda\right)\right)
$$

The equilibrium production of firm $i$ is

$$
q_{t}^{i}=q_{t}\left(p^{*}, \lambda^{i}\right)=\frac{1}{\lambda^{i}} q_{t}^{i}\left(p^{*}, 1\right)=\frac{\Lambda}{\lambda^{i}} q_{t}^{i}\left(p^{*}, \Lambda\right)
$$

\section{Proof of Corollary 1}

At the market equilibrium, the price $p^{*}$ satisfies:

$$
p^{*}=P\left(q_{1}\left(p^{*}, \Lambda\right)+q_{2}\left(p^{*}, \Lambda\right)\right)=P\left(\Phi\left(p^{*}\right) / \Lambda\right) .
$$

taking the derivative w.r.t. $\Lambda$ :

$$
\frac{\partial p^{*}}{\partial \Lambda}=-\frac{P^{\prime}}{\Lambda^{2}} \Phi+\frac{P^{\prime}}{\Lambda} \Phi^{\prime} \frac{\partial p^{*}}{\partial \Lambda}
$$

Then, the sum $\Phi$ is increasing with respect to $p$ (from 18), $P^{\prime}$ is negative, so, $p^{*}$ is increasing with respect to $\Lambda$. 
A reduction of the risk aversion of one firm or the entry of a new firm are both equivalent to a reduction of $\Lambda$ and induce a reduction of the equilibrium price. From Lemma 1, the share of technology 1 increases in each firm portfolio and in the industry portfolio.

\section{Existence and uniqueness of a Cournot equilibrium}

Let us first show that there is a unique Cournot equilibrium. To do so we write the reaction function of firms as functions of the total production and look for a fixed point.

Let us denote $R(Q, \lambda)$ the solution of the equation:

$$
R=\frac{1}{\lambda} \Phi\left(P(Q)+P^{\prime}(Q) R\right)
$$

the solution of this equation is unique because the right hand side is continuous and decreasing w.r.t. $R$ (because $P^{\prime}<0$ and $\Phi$ is increasing). $R(Q, \lambda)$ is the production of a firm with risk aversion $\lambda$ when total production is $Q$. This function is differentiable by part and

$$
\frac{\partial R}{\partial Q}=-\frac{\Phi^{\prime}}{\lambda}\left(P^{\prime}+P^{\prime \prime} R\right)+\frac{\Phi^{\prime}}{\lambda} P^{\prime} \frac{\partial R}{\partial Q}
$$

Therefore, $R(Q, \lambda)$ is decreasing w.r.t to $Q$ because $P^{\prime}+P^{\prime \prime} R<0$ by assumption A.

At a Cournot equilibrium the total production $Q$ and each firm production $q^{i}$ satisfy $q^{i}=R\left(Q, \lambda^{i}\right)$; therefore, the total production is a solution of the equation:

$$
Q=\sum_{i \in I} R\left(Q, \lambda^{i}\right) .
$$

This equation as a solution which is unique (the R.H.S. is decreasing w.r.t. $Q$ because so is $R(Q, \lambda)$ ). Therefore, there is a unique Cournot equilibrium. The total production is the solution of (29) and firms' productions are the unique solutions of

$$
\begin{aligned}
& q^{i}=R\left(Q, \lambda^{i}\right) \\
& q_{t}^{i}=q_{t}\left(P+P^{\prime} q^{i}, \lambda^{i}\right)=\frac{1}{\lambda^{i}} q_{t}\left(P+P^{\prime} q^{i}, 1\right)
\end{aligned}
$$

\section{Proof of Proposition 4}

At the Cournot equilibrium $q^{i}=R\left(Q, \lambda^{i}\right)$ and the function $R(Q, \lambda)$ is striclty decreasing w.r.t. $\lambda$ when positive (by differentiation of 27 ). So,

$$
\lambda^{i} \leqslant \lambda^{j} \Leftrightarrow q^{i} \geqslant q^{j}
$$

Then, let us show that

$$
\lambda^{i} \leqslant \lambda^{j} \Rightarrow \frac{q_{1}^{i}}{q^{i}} \geqslant \frac{q_{1}^{j}}{q_{j}}
$$


We proceed by contradiction and assume that there are two firms $i, j \in I$, $i \neq j$ such that $\lambda^{i}<\lambda^{j}$ and $q_{1}^{i} / q^{i}<q_{1}^{j} / q^{j}$. By Lemma $1 q_{1}(p, 1) / \Phi(p)$ is increasing w.r.t. to $p$, so (by 31) $P+P^{\prime} q^{i}>P+P^{\prime} q^{j}$ and $q^{i}<q^{j}$ a contradiction.

The Proposition follows from 32 and 33.

\section{Proof of Corollary 2}

We consider a decrease of the risk aversion of firm $i \in I$. The cournot equilibrium production is the solution of equation (29). A decrease of $\lambda^{i}$ increase the righthand-side for all $Q$, so the total production increases. We prove the three first points of the Corollary

- For firm $j \neq i$, its production $R\left(Q, \lambda^{j}\right)$ decreases because $R$ decreases w.r.t. $Q$ (point (ii)).

- Concerning firm $i$, its production increases because the total production increases and all other firms production decreases (point(i)).

- The marginal revenue of all firms decreases:

- for firm $i, P(Q)+P^{\prime}(Q) q^{i}$ decreases because $Q$ and $q^{i}$ increases,

- for firm $j \neq i, P(Q)+P^{\prime}(Q) q^{j}$ decreases because $q^{j}$ decreases and $q^{j}=\Phi\left(P+P^{\prime} q^{j}\right) / \lambda^{j}$, and $\lambda^{j}$ remains unchanged and $\Phi$ is decreasing.

So, from Lemma 1, the share of technology 1 in all firms portfolio increases (point(iii)).

\section{Generalisation}

\section{Expected utility}

Technology 1 is not used at equilibrium if there is $q_{2}$ such that

$$
\mathbb{E}\left[U^{\prime}(\pi)\left(p-\theta_{2}-c_{2}\right)\right]=0 \text { and } \mathbb{E}\left[U^{\prime}(\pi)\left(p-\theta_{1}-c_{1}\right)\right] \leq 0
$$

The left equality should be rewritten: $0=\mathbb{E}[\pi]\left(p-c_{2}\right)-\operatorname{cov}\left(U^{\prime}(\pi), \theta_{2}\right)$ and the inequality:

$$
\begin{aligned}
0 & \leq \mathbb{E}\left[U^{\prime}(\pi)\left(p-\theta_{1}-c_{1}\right)\right]=\mathbb{E}[\pi]\left(p-c_{1}\right)-\operatorname{cov}\left(U^{\prime}(\pi), \theta_{2}\right) \\
& \leq \operatorname{cov}\left(U^{\prime}(\pi), \theta_{2}\right) \frac{p-c_{1}}{p-c_{2}}-\operatorname{cov}\left(U^{\prime}(\pi), \theta_{2}\right)
\end{aligned}
$$

\section{Coherent risk measure}

Consider the function $\tilde{\rho}\left(q_{1}, q_{2}\right)=\rho\left(\theta q_{1}+\theta_{2} q_{2}\right)$. We assume that it is homogeneous of degree one, consequently its derivatives are homogeneous of degree zero:

$$
\frac{\partial \tilde{\rho}}{\partial q_{t}}\left(r q_{1}, r q_{2}\right)=\frac{\partial \tilde{\rho}}{\partial q_{t}}\left(q_{1}, q_{2}\right)
$$


Let us also assume that $\tilde{\rho}$ is strictly convex. For each firm there is a unique couple of maximizing quantities, if firm $i$ invest in both quantities the first-order conditions are

$$
p-c_{t}=\lambda^{i} \tilde{\rho}\left(q_{1}^{i}, q_{2}^{i}\right) \frac{\partial \tilde{\rho}}{\partial q_{t}}\left(q_{1}^{i}, q_{2}^{i}\right)=\tilde{\rho}\left(\lambda^{i} q_{1}^{i}, \lambda^{i} q_{2}^{i}\right) \frac{\partial \tilde{\rho}}{\partial q_{t}}\left(\lambda^{i} q_{1}^{i}, \lambda^{i} q_{2}^{i}\right)
$$

the quantities $\lambda^{i} q_{1}^{i}$ are the solutions of a couple of equations independent from $\lambda_{i}$ so that they are independent of $\lambda^{i}$. It ensures that the functions $q_{t}(p, \lambda)$ are homogeneous of degree -1 with respect to $\lambda$.

\section{References}

Aïd, R., Chemla, G., Porchet, A. and Touzi, N. (2011). Hedging and vertical integration in electricity markets, Management Science 57(8): 1438-1452.

Amihud, Y. and Lev, B. (1981). Risk reduction as a managerial motive for conglomerate mergers, The Bell Journal of Economics 12(2): 605-617.

Appelbaum, E. and Katz, E. (1986). Measures of risk aversion and comparative statics of industry equilibrium, The American Economic Review 76(3): 524529 .

Artzner, P., Delbaen, F., Eber, J.-M. and Heath, D. (1999). Coherent measures of risk, Mathematical finance $\mathbf{9}(3)$ : 203-228.

Asplund, M. (2002). Risk-averse firms in oligopoly, International Journal of Industrial Organization 20(7): 995-1012.

Awerbuch, S. and Berger, M. (2003). Energy Security and Diversity in the EU: A Mean-Variance Portfolio Approach, IEA Research Paper.

Banal-Estanol, A. and Ottaviani, M. (2006). Mergers with Product Market Risk, Journal of Economics \& Management Strategy 15(3): 577-608.

Bar-Lev, D. and Katz, S. (1976). A portfolio approach to fossil fuel procurement in the electric utility industry, The Journal of Finance 31(3): 933-947.

Baron, D. P. (1970). Price uncertainty, utility, and industry equilibrium in pure competition, International Economic Review 11(3): 463-480.

Baron, D. P. (1971). Demand uncertainty in imperfect competition, International Economic Review 12(2): 196-208.

Blair, R. (1974). Random input prices and the theory of the firm, Economic Inquiry 12(2): 214-226.

Cronqvist, H., Makhija, A. K. and Yonker, S. E. (2012). Behavioral consistency in corporate finance: Ceo personal and corporate leverage, Journal of Financial Economics 103(1): 20-40. 
Dhrymes, P. J. (1964). On the theory of the monopolistic multiproduct firm under uncertainty, International Economic Review 5(3): 239-257.

Diamond, P. A. (1967). The role of a stock market in a general equilibrium model with technological uncertainty, The American Economic Review 57(4): 759776 .

Ehrenmann, A. and Smeers, Y. (2011). Generation capacity expansion in a risky environment: a stochastic equilibrium analysis, Operations research 59(6): 1332-1346.

Fan, L., Hobbs, B. F. and Norman, C. S. (2010). Risk aversion and $\mathrm{CO}_{2}$ regulatory uncertainty in power generation investment: Policy and modeling implications, Journal of Environmental Economics and Management 60(3): 193 208.

Green, R. (2006). Investment and Generation Capacity, in F. Lévêque, Competitive Electricity Market and Sustainability, Edward Elgar .

Haruna, S. (1996). Industry equilibrium, uncertainty, and futures markets, International Journal of Industrial Organization 14(1): 53-70.

Humphreys, H. and McClain, K. (1998). Reducing the impacts of energy price volatility through dynamic portfolio selection, The Energy Journal 19(3): 107-132.

Leland, H. (1972). Theory of the firm facing uncertain demand, The American Economic Review 62(3): 278-291.

Markowitz, H. (1952). Portfolio selection, The Journal of Finance 7(1): 77-91.

May, D. O. (1995). Do managerial motives influence firm risk reduction strategies?, The Journal of Finance 50(4): 1291-1308.

Meunier, G. (2013). Risk aversion and technology mix in an electricity market, Energy Economics 40: 866-874.

McKinnon, R. I. (1967). Futures markets, buffer stocks, and income stability for primary producers, The Journal of Political Economy 75(6): 844-861.

Moschini, G. and Lapan, H. (1995). The hedging role of options and futures under joint price, basis, and production risk, International Economic Review 36(4): 1025-1049.

Nance, D. R., Smith, Clifford W., J. and Smithson, C. W. (1993). On the determinants of corporate hedging, The Journal of Finance 48(1): 267-284.

Neuhoff, K. and De Vries, L. (2004). Insufficient incentives for investment in electricity generations, Utilities Policy 12(4): 253-267. 
Newbery, D. and Stiglitz, J. (1981). The theory of Commodity Price Stabilization.

Okuguchi, K. (1977). Input Price Uncertainty and the Theory of the Firm, Economic Studies Quarterly 28: 25-30.

Roques, F. A., Newbery, D. M. and Nuttall, W. J. (2008). Fuel mix diversification incentives in liberalized electricity markets: A mean-variance portfolio theory approach, Energy Economics 30(4): 1831-1849.

Sandmo, A. (1971). On the theory of the competitive firm under price uncertainty, The American Economic Review 61(1): 65-73.

Sharpe, W. (1991). Capital asset prices with and without negative holdings, The Journal of Finance 46(2): 489-509.

Stewart, M. (1978). Factor-price uncertainty with variable proportions, The American Economic Review 68(3): 468-473.

Tessitore, A. (1994). Market segmentation and oligopoly under uncertainty, Journal of Economics and Business 46(2): 65-75.

Wambach, A. (1999). Bertrand competition under cost uncertainty, International Journal of Industrial Organization 17(7): 941 - 951.

Wolak, F. and Kolstad, C. (1991). A model of homogeneous input demand under price uncertainty, The American Economic Review 81(3): 514-538.

Zakamouline, V. and Koekebakker, S. (2009). Portfolio performance evaluation with generalized sharpe ratios: Beyond the mean and variance, Journal of Banking 83 Finance 33(7): 1242-1254. 